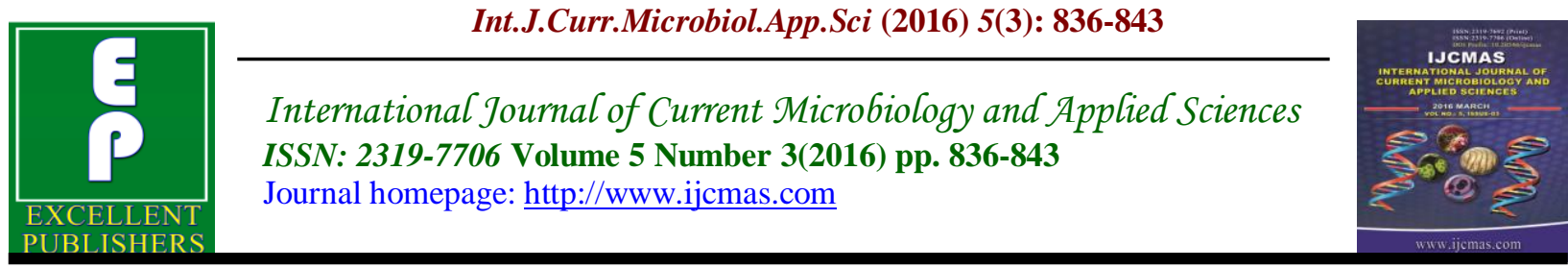

Original Research Article

http://dx.doi.org/10.20546/ijcmas.2016.503.097

\title{
Effect of the Fungus Pochonia chlamydosporia on Contracaecum pelagicum Eggs
}

\author{
Fabio Ribeiro Braga ${ }^{1,2,3 *}$, Filippe Elias de Freitas Soares², Tiago Senna ${ }^{2}$, \\ Thiago de Hollanda Aype, Leandro Abreu da Fonseca ${ }^{1}$, Tracy Lacerda ${ }^{2}$, \\ Anderson Rocha Aguiar $^{2}$, Luis Felipe Mayorga ${ }^{2}$ and Jackson Victor de Araújo ${ }^{1}$ \\ ${ }^{1}$ Departamento de Veterinária, Universidade Federal de Viçosa, Viçosa, MG, Brazil \\ ${ }^{2}$ Universidade Vila Velha, Vila Velha ES, Brazil \\ ${ }^{3} \mathrm{CNPq}$ Scholarship, Brazil \\ *Corresponding author
}

\section{A B S T R A C T}

\section{Keywords}

Ovicidal fungus,

Magellanic

penguin,

Contracaecum

pelagicum,

Biological

Control

\section{Article Info}

Accepted:

15 January 2016

Available Online:

10 March 2016
The genus Contracaecum (Ascaridida: Anisakidae) is a nematode parasite belonging to fish-eating birds throughout the world. $C$. pelagicum causes gastrointestinal problems in the Magellanic penguin. The objective of this study was to evaluate the effect of an ovicidal fungus (Pochonia chlamydosporia) on C.pelagicum eggs under different concentrations (500, 1500, 2000, and 3000 per Petri dish).The ovicidal effect was evaluated in accordance with the visualized morphological changes tothe eggshell: type 1, physiological effect without morphological damage to the egg shell; type 2, lytic effect with morphological alteration of the eggshell; and type 3, lytic effect with morphological alteration to the egg shell and embryo in addition to hyphal penetration and internal egg colonization. At the end of the experiment, there was significant difference in egg destruction (effect type 3 ) in the four tested concentrations when compared to the control group. No difference was observed $(\mathrm{P}>0.01)$ for ovicidal activity between the four concentrations used. At the concentration of 3000 chlamydospores, a $46.2 \%$ of $C$. pelagiucum egg destruction was observed, after 7 days. A concentration of at least 500 chlamydospores was effective in destroying $C$. pelagicum eggs, suggesting a potential use for chlamydospores ( $P$. chlamydosporia) against this nematode.

\section{Introduction}

The genus Contracaecum (Ascaridida: Anisakidae), is a nematode parasite belonging to fish-eating birds throughout the world (Girisgin et al. 2012). There is usually a varied helminth fauna in waterfowl and thus, normally literature reports that the helminths most found in these animals are nematodes of the Order Ascaridea, and the Anisakidae family, having great zoonotic potential (Martins et al. 2003, Carvalho et al., 2012). Anisakids are associated to aquatic organisms (fish and marine 
mammals) as well as fish-eating birds, and therefore considered in this context. The Magellanic penguin (Spheniscus magellanicus) is present in South America, with populations distributed along the Patagonian coast (Argentina and Chile) and the Falkland Islands, with the highest abundance among the penguins of temperate areas. According to Mayorga et al. (2011), some factors have been implicated in the weakening and mortality of Magellanic penguins during migration, among them are: (1) contamination of the oceans with oil and its derivatives, (2) accidents with fishing nets, (3) ingestion of anthropogenic waste, and (4) gastrointestinal parasites (Martins et al., 2003; Carvalho et al. 2012).

The genus Contracaecum (Railliet \& Henry, 1912) contains approximately 50 nematode species, of which the mature ones parasitize fish-eating birds and mammals. Their complex life cycle consists of four larval stages and involves copepods, aquatic vertebrates, and fish as intermediate and/ or paratenic hosts. Nematodes belonging to the Anisakidae family, such as the C. pelagicum, may cause a disease in humans known as anisaki dose. When in the stomach of the definitive host, L3 moults to L4 and both the larvae and the adults may negatively affect the host's health (Anderson et al. 2002, Martins et al. 2005, Karnek \& Bohdanowicz, Girisgin et al. 2012).

In Brazil, several studies were conducted in watersheds mentioning the occurrence of helminths of hygienic-sanitary interest occurring in piscivorous fish and in waterfowl, and among these the Magellanic Penguin (Santos et al., 1984; Garbin et al., 2007; Ederli et al., 2009). In these birds the changes observed by $C$. pelagicum are related to inflammatory processes and obstruction. In this context, Rezende et al. (2009),reports that the parasite community of a species can reveal important information about their biology and ecology. Parasitological studies on penguins, as well as other migratory animals, may indicate seasonal changes in diet and temporary trophic relationships during migration.

Egg parasitism by means of fungi isan important biological phenomenon that occurs in species such as: Pochonia chlamydosporia (syn. Verticillium chlamydosporium Goddard), Paecilomyces lilacinus and Dactyella ovoparasitica; its main representatives with significant ovicidal activity (Lysek and Sterba, 1991). After an extended observational study, Lysek (1976) established a qualitative method used to sort ovicidal activity. This method, first proposed on Ascaris lumbricoides eggs, determined that the action mechanism ofan opportunistic fungus is based on three basic types of ovicidal activity, with seven subtypes:(1) physiological, with biochemical effects and no morphological damage to the egg shell;(2) lithic biochemical effect, with progressive morphological alterations to the eggshell and damage to the embryo; and (3) lithic and morphological effect, with egg penetration, attack and death to the embryo.

The Pochonia genre is one of the most studied for the control of helminths potentially harmful to agriculture, and currently, combate against their eggs is also being emphasized. The fungus $P$. chlamydosporia was found in Alabama USA, in 1981, parasiting Meloydogine sp eggs and females, being considered as one of the most promising agents for the management and control of problems caused by nematodes. It is also successfully employed in reducing the rate of hatching Ascaris lumbricoides eggs (Lysek, 1976; Hidalgo et al., 2000). In this context, studies on the interaction of the ovicidal fungus, 
Pochonia chlamydosporia, are justified by its importance in public health, due to the high resilience that geohelminths eggs have when present in the external environment, acting directly or indirectly as a source of contamination to humans, since the use of nematophagous fungi present in the environment as biological controllers and the viability of environmental dispersion of resistant fungal structures (chlamydospores) can act decontaminating the environment (Lysek et al., 1982; Braga et al., 2011b, Braga and Araujo, 2014).

Regarding the use of fungi with proven ovicidal activity, they may be useful as a complementary tool, even under experimental conditions, for control of helminth eggs, such as $C$. pelagicum eggs.

Thus, experimental studies that consider alternative measures for controlling these parasites are welcome, as the use of fungi helminth "eaters" (Braga and Araújo, 2012).In the present study we aimed to evaluate the effect of an ovicidal fungus on the eggs of the gastrointestinal nematode C.pelagicum.

\section{Material and Methods}

In the present study, an isolate of the nematophagous fungus $P$. chlamydosporia (VC4) was used. This isolate derived from Brazilian soil, and was maintained by means of continuous transfer of solid culture media in the Laboratory of ParasitologyDepartment of Veterinary Medicine from the Federal University of Viçosa.

C. pelagicum eggs were obtained by dissection of the uterus belonging to adult female specimens recovered during the necropsy of a Magellanic penguin (Spheniscus magellanicus) at the Institute for Research and Rehabilitation of Marine
Animals (IPRAM), located in the state of Espírito Santo. The identification of adult individuals and eggs followed the criteria established by Yamaguti et al. (1961), and Taylor et al. (2007). Later, the eggs were washed 10 times with distilled water by centrifugation at $1000 \mathrm{rpm}$ for $5 \mathrm{~min}$, discarding the supernatant after each centrifugation.

Then, from the edges of the fungal colonies grown free of contamination, agar disks with approximately $4 \mathrm{~mm}$ in diameter, were removed with the aid of a platinum loop and inoculated in Petri dishes containing $20 \mathrm{ml}$ of YPSSA medium. Following, these plates were incubated in an environmental chamber at $25^{\circ} \mathrm{C}$ for 28 days and in the absence of light. After this period, the surfaces of the plates were washed with distilled water with the aid of a brush. The suspension contained in the plaques was passed through a sieve attached to a plastic container for removal of mycelium fragments. Chlamydospore identification was performed in accordance with Gams and Zare (2001). The spores recovered were quantified in ten counts in a Neubauer chamber and qualified (chlamydospores) according to three aliquots of $10 \mu \mathrm{L}$. After quantification and qualification of the spores, the dilution for the desired concentrations (500, 1500, 2000, and 3000) was performed.

To compose the experimental assay, the $C$. pelagicum eggs were transferred over the surface of Petri dishes $(9.0 \mathrm{~cm}$ in diameter) containing $2 \%$ WA medium in the following concentrations of chlamydospores (500, 1500, 2000, and 3000). Six repetitions were performed for each group. In the treatments, each plate contained one thousand $C$. pelagicum eggs with one of the concentrations; and the control group only one thousand eggs. In the intervals of 5 and 
7 days, one hundred eggs were removed from each plate of both the treated and control groups, without chlamydospores according to the technique described by Araujo et al.(1995), and then evaluated in 40x objective according to the parameters established by Lysek et al.(1982).The data for each interval studied were subjected to the non-parametric Friedman test with $1 \%$ probability, Ayres et al. (2003).

\section{Results and Discussion}

The percentage results for the effect types 1 , 2 , and 3, during the5 and 7 days of interaction in different chlamydospore concentrations (500, 1500, 2000, and 3000) of the fungus $P$. chlamydosporia (VC4) are shown in Figure 1, demonstrating the percentage of eggs showing only interaction (effect type 1); hyphae adhesion (effect type
2); and finally destruction of the eggs (effect type 3 ).

At the end of the experiment, there was a significant difference $(P<0.01)$ in the destruction of the eggs (effect type 3 ) inthe four tested concentrations compared to the control group. No difference was observed $(P>0.01)$ for ovicidal activity between the four concentrations used. Through light microscopy, using the 40x and 10x objective, it was possible to observe $C$. pelagicum eggs destroyed by the fungus $P$. chlamydosporia (VC4), at the end of the experiment (Figs. 2A-I). The highest percentages for the effect type 3 were observed at concentrations of 2000 and 3000 chlamydospores, at the end of the experiment (7 days) with $45.3 \%$ and $46.2 \%$ destruction, respectively.

Figure.1 Percentages of the ovicidal activity for the effects of types 1,2 and 3 to 5 and 7 days of interaction of chlamydospores of the fungus Pochonia chlamydosporia (VC4) at different concentrations (500, 1500, 2000 and 3000) on eggs of Contracaecum pelagicum and the control group. The asterisk denotes a difference $(P<0.01)$

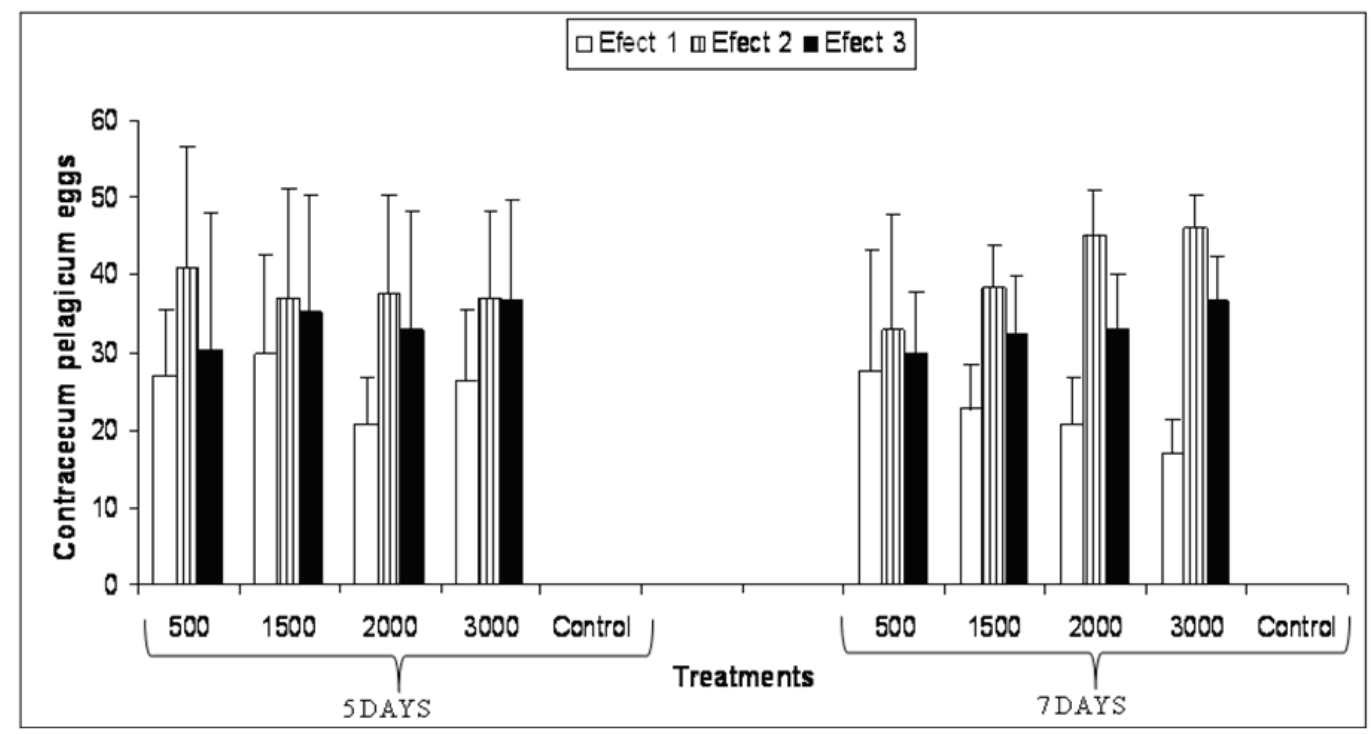


Figure.2A-I Hyphae of the fungus Pochonia chlamydosporia (black arrow) and the eggs of Contracaecum pelagicum destroyed (white arrow) at the end of the experiment. Light microscope. Magnification: $10 \mathrm{x}$ and $40 \mathrm{x}$ objective lens. Bars: A $-156 \mu \mathrm{m}$; B $-182 \mu \mathrm{m}$; C $182 \mu \mathrm{m} ; \mathrm{D}-182 \mu \mathrm{m} ; \mathrm{E}-124.8 \mu \mathrm{m} ; \mathrm{F}-182 \mu \mathrm{m} ; \mathrm{G}-119.6 \mu \mathrm{m} ; \mathrm{H}-104 \mu \mathrm{m}$ and I- $182 \mu \mathrm{m}$



In Magellanic penguins the changes observed by $C$. pelagicum are related to inflammation and obstruction, leading to death in these animals. On the other hand, according to López-Serrano et al. (2000), these parasites have significant public health importance, with description of infections in humans resulting in gastrointestinal perforations, obstructive and allergic reactions. Furthermore, although there are no reports in literature regarding human infection due to Contracecum sp., mammals have been experimentally infected, resulting in harmful effects to the organism and therefore indicating its importance (Barros et al., 2004).
Regarding the use of nematophagous fungi, much has been studied about the percentage differences for their predatory activity(Braga et al., 2011; Araujo et al., 2012). Thus, in this study, the fungus $P$. chlamydosporia (VC4) used at different concentrations, was effective in destroying $C$. pelagicum eggs throughout the experiment. This information indicates that this fungus could be successfully used in the biological control of potentially zoonotic helminths (Araujo et al., 2012). The production of chlamydospores is one of the main characteristics that possibly show if a fungus could be used in the environmental control of gastrointestinal parasitic helminth eggs. 
These structures allow nematophagous fungi the capability of passing through the gastrointestinal tract belonging to domestic animals, as well as being readily dispersed in the external environment then acting as natural dispersers (Araújo et al., 2004).

Another important aspect observed on the efficiency of helminth egg destruction by $P$. chlamydosporia is its growth from culture media known to be "poor". At this point, literature mentions that this fungus behaves in different ways according to the culture medium being used, maintaining their ovicidal ability through contact with the eggs. Eren and Pramer (1965),mention that the periodic supply of nematodes to nematophagous fungi, in a culture medium poor in nutrients, reduces its saprophytic growth increasing its activity as natural antagonist. Starting from this premise, in a recent study Braga et al.(2011)proposed that not only the culture medium, but also the amount of chlamydospores being used in the in vitro control of helminth eggs, were two important characteristics from abiological point of view. In the present study, we observed that the concentrations of 2000 and 3000 chlamydospores presented the highest ovicidal percentages. Thus, the results once again suggest that the chlamydospore concentration and the 2\% WA medium, even though considered to be a "poor" culture medium, may influence egg predation.

Paperna (1964), reports that fish can serve as definitive, intermediate, or paratenic (transport) hosts in the life cycles of many parasite species and usually affect the marketability of commercially produced fish, thus raising a lot of public health concerns, especially in areas where raw or smoked fish are consumed. In this sense, a wide variety of helminth genera suggest the use of "bio controller agents" in several studies under laboratory conditions. In this context, literature also reports some studies where nematophagous fungi species have demonstrated their activity on helminth eggs and larvae belonging tobirds, which can represent, in the future, an alternative control (Braga et al., 2012, 2013). Yáñez et al. (2012,) described gastric ulceration caused by Contracaecum in mammals and birds (such as penguins), but this is the first report of an ovicidal fungus infection on $C$. pelagicum eggs from a $M$. penguin.

\section{Acknowledgments}

The authors thank, FAPES, CNPq, CAPES and FAPEMIG for their financial support.

\section{References}

Anderson, R.C.2000. Nematode parasites of vertebrates: their development and transmission. 2.ed. Wallingford, UK: CAB International,650p.

Araujo, J.M., Araújo, J.V., Braga, F.R., Araújo, D.M., Ferreira, S.R., Soares, F.E.F., Benjamin, L.A. 2012.Survival of Pochonia chlamydosporia in the gastrointestinal tract of experimentally treated dogs. Res. Vet. Sci.,12:803806.

Araújo, J.V., Mota, M.A.,Campos, A.K. 2004. Controle de helmintos de animais por fungos nematófagos. Rev. Bras. Parasitol. Vet., 13: 165-169.

Araújo, M.A., Santos, S.,Ferraz,S. 1995. Efeito ovicida de fungos nematófagos sobre ovos embrionados de Toxocara canis. Arq. Bras. Med. Vet. Zoot.,47:37-42.

Ayres, M.,Ayres, J.M.R., Ayres, D.L., Santos, A.S. 2003. Aplicações estatísticas as áreas de ciências biológicas. Belém: Sociedade civil mamirauá: Brasília CNPq. p. 290.

Barros, L.A., Torttelly, R., Pinto, R.M., Gomes,D.C. 2004.Effects of 
experimental infections with larvae of Eustrongylides ignotus Jäegerskiold, 1909 and Contracaecum multipapillatum (Drasche, 1882) Baylis, 1920 in rabbits. Arq. Bras. Med. Vet. Zootec.56:325-332.

Braga, F.R., and Araújo, J.V. 2011. Helminthiasis control of domestic animals, a new approach to an old problem. In: Paz Silva, A; AriasVazquez, M.S. (Org.). Fungi: Types, Environmental Impact and Role in Disease. Nova York: Nova Science Publishers. p. 7-10.

Braga, F.R., Araújo, J.V., Araujo, J.M., Frassy, L.N., Tavela,A.O., Soares, F.E.F., Carvalho, R.O., Queiroz, L.M., Queiroz, J.H. 2012.Pochonia chlamydosporia fungal activity in a solid medium and its crude extract against eggs of Ascaridia galli. J. Helminthol., 86:348-352.

Braga, F.R., Araújo, J.V., Tavela, A.O., Vilela, V.L.R., Soares, F.E.F., Araujo, J.M., Queiroz, L.M., Silveira, W.F., Feitosa, T.F., Dantas, E.S., Athayde, A.C.R. 2013.First report of the interaction of nematophagous fungi on Libyostrongylus douglassii

(Nematoda: Trichostrongilidae) of ostrich. Rev. Bras. Parasitol. Vet., 22:147-151.

Braga, F.R., Silva, A.R., Carvalho,R.O., Araújo, J.V.,Pinto, P.S.A. 2011.Ovicidal activity of different concentrations of Pochonia chlamydosporia chlamydospores on Taenia taeniaeformis eggs. $J$. Helminthol. 85:7-11.

Carvalho, C.O., Cuenca, S.C., Kleeb, S.R., Gallo, H., Baldassin, P. 2012.Gross and histopathological findings in magellanic penguins Spheniscus magellanicus Forster, 1781). Arq. Bras. Med. Vet. Zootec.,64:769-772.

Ederli, N.B., Oliveira, F.C.R., Monteiro,
C.M., Silveira, L.S.,Rodrigues, M.L.A. 2009. Ocorrência de Contracaecum pelagicum Johnston \& Mawson, 1942 (Nematoda, Anisakidae), em pinguimde-magalhães

(Spheniscus magellanicus Forster, 1781) (Aves, Spheniscidae) no litoral do Espírito Santo. Arq. Bras. Med. Vet. Zootec.,61:1006-1008.

Eren, J.,and Pramer,D. 1965. The most probable number of nematodetrapping fungi in soil. Soil Science, 99:285.

Gams, W., and Zare, R. 2001.A revision of Verticillium sect. Prostrata. III. Generic classification. Nova Hedwigia.73:329-337.

Garbin, L.E., Navone, G.T., Diaz, J.I., Cremont, F. 2007.Further study of Contracaecum pelagicum (Nematoda: Anisakidae) in Spheniscus magellanicus (Aves: Spheniscidae) from Argentinean coasts. $J$. Parasitol.,93:143-150.

Girisgin, A.O., Alasonylilar-demirer, A. 2005. A Case of Contracaecum sp. (Ascaridida: Anisakidae) Infection in Dalmatian Pelican (Pelecanus crispus) afkas.Univ. Vet. Fak. Derg., 18:227229.

Kanarek, G., and Bohdanowicz, J. 2009. Larval Contracaecum sp. (Nematoda: Anisakidae) in the Great Cormorant [Phalacrocorax carbo (L., 1758)] from north-eastern Poland: A morphological and morphometric analysis. Vet. Parasitol.,166: 90-97.

López-Serrano, M.C., Gomez,A.A., Daschner, A., Morenoancillo, J.M.S., De Parga, M.T., Caballero, M.,Barranco, P.,Cabañas, R. 2000.Gastroallergic anisakis: Findings in 22 patients. J. Gastroent. Hepatol., 15:503-506.

Lysek, H., Fassatiová,O., Pineda, N.C., Hernández, N.L. 1982.Ovicidal fungi 
in soils of Cuba. Folia Parasitol., 29:265-270.

Martins, M.L., Santos,R.S., Marengoni, N.G., Takahashi, H.K., Fujimoto, R.Y. 2003.Infection and susceptibility of three fish species from the Paraná River, Presidente Epitácio, SP, Brazil to Contracaecum sp. larvae (Nematoda: Anisakidae). Acta Scient.,25:73-78.

Martins, M.L., Onaka, E.M., Fenerick, J. 2005. Larval Contracaecum sp. (Nematoda: Anisakidae) in Hoplias malabaricus and Hoplerythrinus unitaeniatus (Osteichthyes: Erythrinidae) of economic importance in occidental marshlands of Maranhao, Brazil. Vet. Parasitol., 127: 51-59.

Mayorga, L.F.S.P., Renata, C.C., Bhering, L., Medeiros, C.C., Costa, L.M.B. 2011.Instituto de Pesquisa e Reabilitação de Animais Marinhos, Boletim N.2, Pinguins no Brasil.

Paperna, I. 1964. Parasitic helminths of inland-water fishes in Israel. Israel $\mathrm{J}$. Zoo.,13: 1-26
Rezende, G.C. 2009. Aspectos Ecológicos da Helmintofauna de Pinguins-deMagalhães, Spheniscus magellanicus (Aves: Spheniscidae), procedentes do Litoral Norte do Estado de São Paulo. Dissertação de Mestrado.

Santos, C.P. 1984. Um nematódeo parasita do pinguim Spheniscus magellanicus (Forster) (Ascaridoidea, Anisakidae). Mem. Inst. Oswaldo Cruz., 79: 233237.

Taylor, M.A.,Coop, R.L.,Wall, R.L. 2007.Vet. Parasitol., $3^{\mathrm{a}}$ ed,468p.

Yamaguti, S. 1961. Systema Helminthum Nematodes. Vol. III. - Part I e II. London: Interscience Publishers. $1261 \mathrm{p}$.

Yáñez, F., Fernández, I., Campos, V.V., Mansilla, M., Valenzuela, A., González, H., Rodríguez, C., Rivas, M., Alveal, K.,Oyarzún, C. 2012.First pathological report of parasitic gastric ulceration in Humboldt penguin (Spheniscus humboldti) along the coast of south-central Chile. Lat. Am. J. Aquat. Res., 40:448-452.

\section{How to cite this article:}

Fabio Ribeiro Braga, Filippe Elias de Freitas Soares, Tiago Senna, Thiago de Hollanda Aype, Leandro Abreu da Fonseca, Tracy Lacerda, Anderson Rocha Aguiar, Luis Felipe Mayorga and Jackson Victor de Araújo. 2016. Effect of the Fungus Pochonia chlamydosporia on Contracaecum pelagicum Eggs. Int.J.Curr.Microbiol.App.Sci. 5(3): 836-843. doi: http://dx.doi.org/10.20546/ijcmas.2016.503.097 